\title{
PERANCANGAN SEMI GANTRY CRANE KAPASITAS 10 TON DENGAN BANTUAN SOFTWARE
}

\author{
Joseph Rama Wiratama' ${ }^{1)}$ dan Soeharsono ${ }^{2)}$ \\ ${ }^{1)}$ Program Studi Teknik Mesin Fakultas Teknik Universitas Tarumanagara \\ ${ }^{2)}$ Jurusan Teknik Mesin Universitas Trisakti \\ e-mail: joseph_thephoenix@yahoo.com
}

\begin{abstract}
Indonesia which is an archipelago country has a lot of harbour for conveying and delivering goods which is stored in container from one island to another island. Containers are very heavy so that required a strong and stable lifting machine, also have a good performance and safety. Semi gantry crane as one of the example of lifting machine is designed using assistance of software for that purpose.
\end{abstract}

Keywords: harbour, container, semi gantry crane

\section{PENDAHULUAN}

Indonesia dikenal sebagai sebuah Negara Kepulauan karena memiliki pulau berjumlah 17.504 buah berdasarkan data Departemen Dalam Negeri Republik Indonesia tahun 2004. Hal ini menyebabkan pulau-pulau di Indonesia memiliki banyak pelabuhan sebagai salah satu sarana transportasi antar pulau. Salah satu kegiatan yang dapat diamati di pelabuhan adalah pengangkutan barang dalam jumlah banyak yang tersimpan di dalam peti kemas (container) dengan menggunakan kapal laut. Peti kemas tidak mudah untuk dipindahkan karena selain berat juga memiliki ukuran yang besar. Sehubungan dengan hal ini, maka diperlukan sebuah alat yang dapat digunakan untuk mengangkat dan memindahkan peti kemas. Alat tersebut adalah crane.

Crane terdiri dari lima jenis utama. Salah satu dari kelima jenis tersebut adalah crane tipe jembatan. Kelompok crane tipe jembatan terdiri atas crane yang berjalan pada gelagar-rangka dan yang bergerak pada jalur rel yang dibentang pada dinding bangunan atau di permukaan tanah. Untuk rel yang dibentangkan di permukaan tanah, jembatan dilengkapi dengan kaki pendukung yang dipasang pada kedua sisi jembatan (gantry crane) atau hanya pada satu sisi jembatan (semi gantry crane).

Pada perancangan semi gantry crane berkapastias 10 ton ini akan dilakukan pengujian dengan bantuan software Autodesk Inventor Professional 2012 agar diperoleh desain yang stabil, kuat, dan aman. Semua faktor-faktor tersebut perlu diperhatikan mengingat bahaya yang timbul dari kerusakan mesin dimana kerusakan tersebut dapat menyebabkan muatan yang sedang diangkat jatuh sehingga mengakibatkan kerusakan pada muatan serta mengancam jiwa manusia.

Permasalahan selalu timbul dalam setiap penelitian sehingga perlu dilakukan identifikasi masalah untuk memudahkan proses penelitian. Permasalahan yang ditemui pada perancangan ini antara lain: dimensi, material yang digunakan dan kekuatan dari tiap komponen crane stabilitas struktur rangka; serta daya dari motor penggerak yang digunakan. Agar pembahasan yang dilakukan tidak meluas, maka diperlukan batasan-batasan masalah seperti: kapasitas angkat muatan 10 ton; span dari crane $15 \mathrm{~m}$; tinggi angkat muatan $8 \mathrm{~m}$; dan komponen yang dirancang adalah tali baja, sistem puli, drum, kait, batang lintang kait, serta struktur rangka yang menggunakan bantuan software.

Kemudian setelah melakukan identifikasi dan membuat batasan masalah, maka rumusan masalah yang didapat adalah merancang komponen-komponen crane yang meliputi: tali baja; sistem puli; drum; kait; batang lintang kait; struktur rangka crane; dan menghitung daya motor penggerak yang dibutuhkan. Lalu tujuan dari penelitian ini adalah mendapatkan rancangan crane yang kuat, stabil, dan aman serta dapat beroperasi dengan baik. 


\section{METODOLOGI PENELITIAN \\ Perancangan Hoist \\ Tali baja}

Tali baja digunakan secara luas pada mesin-mesin pengangkut sebagai perangkat untuk mengangkat dan menurunkan muatan serta memindahkan gaya. Tali baja adalah tali yang dikonstruksikan dari kumpulan jalinan serat-serat baja dengan kekuatan $\sigma_{\mathrm{b}}=1275,3 \mathrm{~N} / \mathrm{mm}^{2}$ sampai $1962 \mathrm{~N} / \mathrm{mm}^{2}$. Beberapa serat dipintal hingga menjadi satu jalinan (strand), kemudian beberapa strand dijalin pula pada suatu ini (core) sehingga membentuk tali baja.

Kerusakan pada rantai akan terjadi tiba-tiba sedangkan pada tali baja, kawat pada bagian luar akan mengalami kerusakan yang lebih parah dan putus lebih dahulu dibandingkan dengan bagian dalam. Sehingga bila bagian luar tali kawat mulai terputus-putus maka itu adalah pertanda bahwa umur tali baja tersebut tidak lama lagi dan perlu segera diganti. Harga tali baja lebih murah dibandingkan dengan rantai, tetapi memerlukan diameter drum yang lebih besar sehingga mekanisme pengangkat lebih besar dan berat.

Kerusakan tali baja disebabkan oleh kelelahan bahan dan mengalami jumlah lengkungan tertentu. Umur pakai tali tergantung pada ukuran puli atau drum, beban, konstruksi tali, faktor metalurgi, produksi, desain, dan kondisi operasi. Ketahanan (batas kelelahan) tali baja ditentukan berdasarkan umur operasi tali baja tersebut.

\section{Puli}

Puli atau katrol adalah cakra (disc) yang dilengkapi dengan tali, merupakan kepingan bundar yang terbuat dari logam ataupun non-logam [2]. Pinggiran cakra diberi alur yang berfungsi sebagai laluan tali untuk memindahkan gaya dan gerak seperti tampak di Gambar 1.

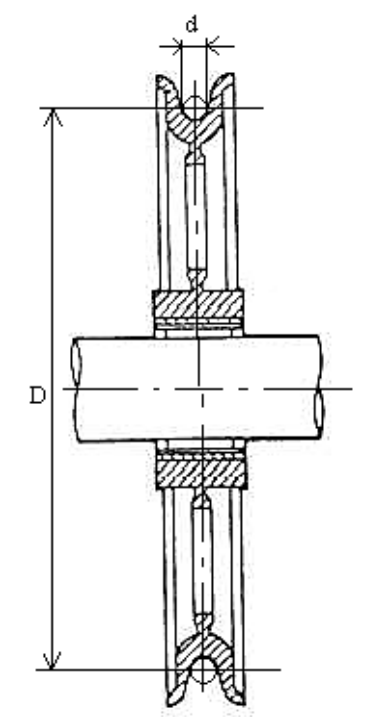

Gambar 1. Konstruksi puli [1]

Sistem puli yang digunakan adalah sistem puli majemuk dengan empat buah puli yang menyangga muatan seperti tampak pada Gambar 2. Sistem puli ini mampu membawa muatan hingga 25 ton. Untuk dapat berputar dan mengurangi gesekan, maka puli dipasang pada gandar yang didukung oleh bantalan luncur. Bahan untuk gandar puli yang digunakan adalah baja S45C.

Jumlah lengkungan untuk sistem puli pada Gambar 2 adalah $(N B)=3$, sebagaimana dijelaskan pada Gambar 3.

\section{Drum}

Drum pada mekanisme pengangkat digunakan untuk menggulung tali. Drum untuk menggulung tali baja terbuat dari besi cor. Untuk drum yang digerakkan dengan mesin maka drum 
dilengkapi dengan alur spiral, sehingga tali akan tergulung secara merata dan mengurangi gesekan serta keausan. Pada perancangan ini, drum memiliki dua alur spiral, yaitu alur spiral kiri dan alur spiral kanan. Dinding drum akan mengalami tegangan tekan, dimana nilai yang diizinkan untuk besi cor tidak boleh melebihi $98,1 \mathrm{~N} / \mathrm{mm}^{2}$ [1].

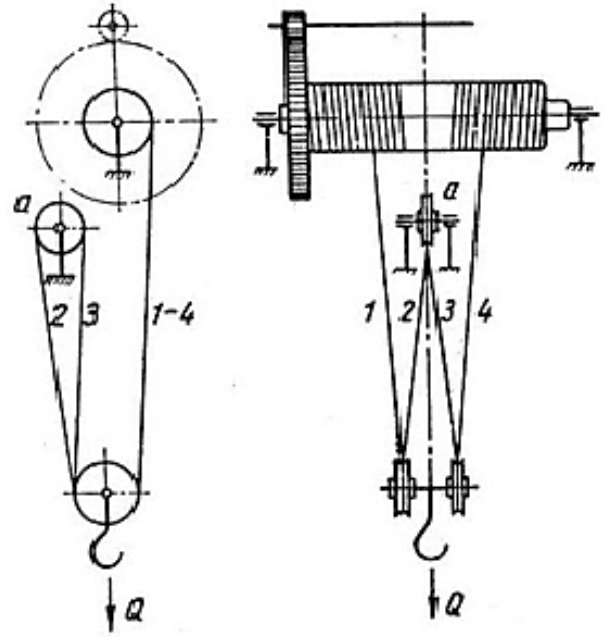

Gambar 2. Sistem puli yang digunakan [1]

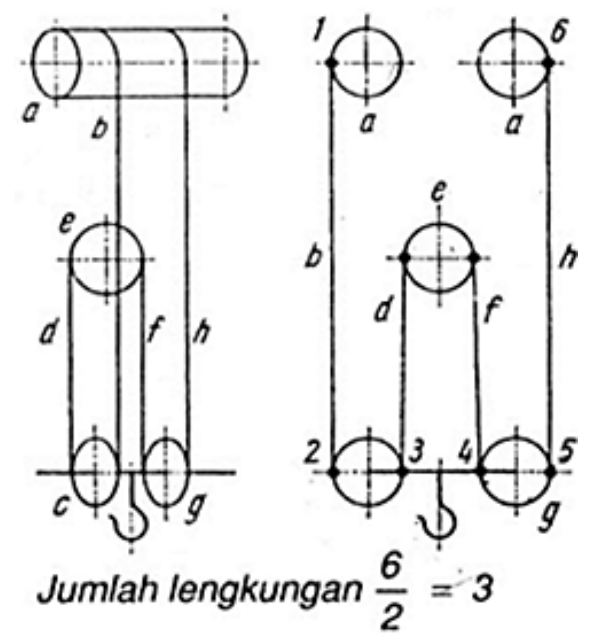

Gambar 3. Jumlah lengkungan tali baja [1]

\section{Kait}

Kait adalah perlengkapan yang digunakan untuk menggantung muatan yang diangkat. Pada ujung tangkai kait terdapat ulir yang digunakan untuk mengikat bantalan aksial agar kait tersebut dapat berputar seperti diperlihatkan di Gambar 4.
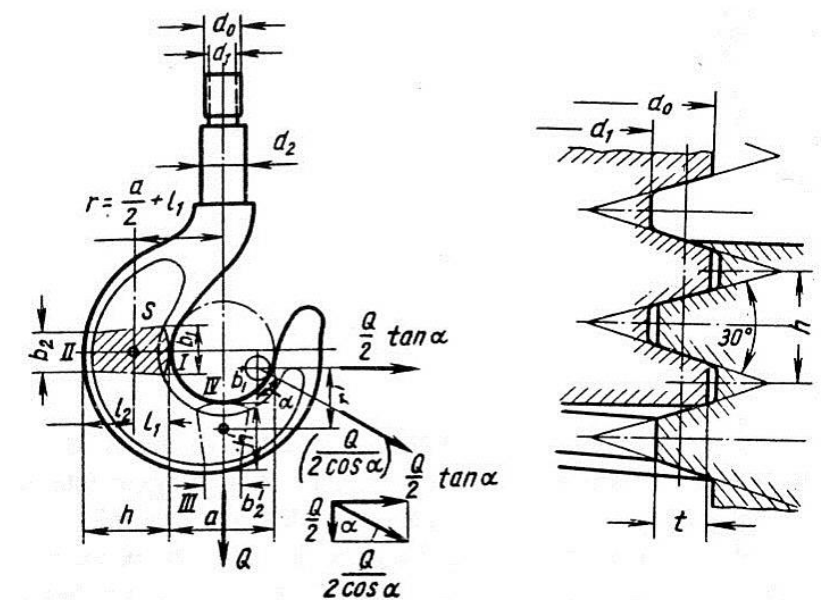

Gambar 4. Kait tunggal dengan ulir trapesium [1]

Kait dibuat dengan cara ditempa pada cetakan rata atau tertutup. Kait standar dapat mengangkat muatan sampai 50 ton. Bagian dudukan kait selain mengalami tegangan geser $(\tau)$, juga mengalami tegangan tarik satuan $\left(\sigma_{t}\right)$ yang terjadi pada bagian penampang terdalam kait (penampang I) dan tegangan tekan satuan maksimum yang terjadi pada bagian terluar kait (penampang II). Nilai kedua tegangan satuan maksimum tersebut tidak boleh melebihi tegangan aman 147,15 N/mm² untuk baja 20 [1].

\section{Batang lintang kait}

Pembuatan model untuk batang lintang kait dibantu oleh software Autodesk Inventor Professional 2012 dengan tujuan untuk memudahkan proses perhitungan tegangan yang terjadi akibat gaya yang dihasilkan oleh muatan yang diangkat. 


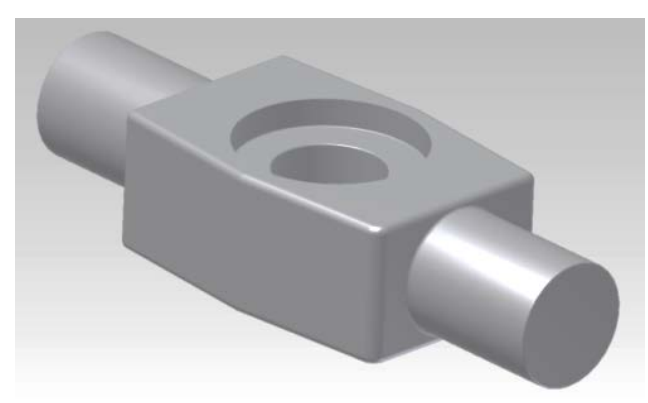

Gambar 5. Model batang lintang kait

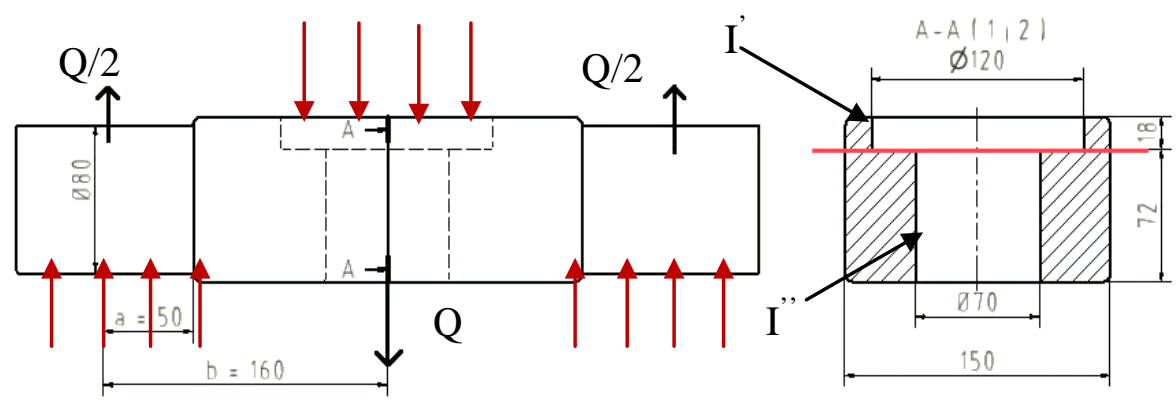

Gambar 6. Dimensi utama batang lintang kait

\section{Perancangan Struktur Rangka}

\section{Pemodelan tiap komponen}

Pada tahap ini, dilakukan proses pemodelan dari masing-masing komponen struktur rangka yang meliputi girder, beam, sambungan gantry, gantry, bottom wheel, dan upper wheel dengan menggunakan software.

\section{Assembly komponen}

Setelah semua komponen selesai dibuat, maka dilakukan proses assembly atau perakitan komponen. Gambar hasil assembly dapat dilihat pada Gambar 7.

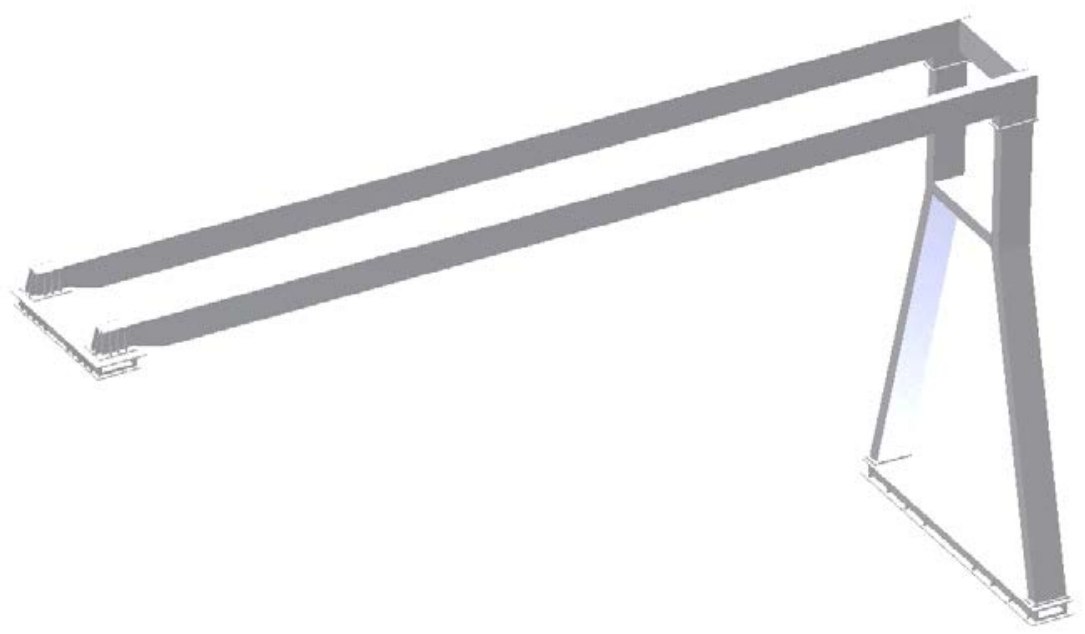

Gambar 7. Model semi gantry crane

\section{Stress analysis}

Stress analysis dilakukan untuk menguji kekuatan dari model yang telah dirancang terhadap pembebanan. Jenis stress analysis yang dilakukan adalah static analysis. Langkah pertama yang perlu dilakukan sebelum memulai simulasi adalah pemilihan material. Material yang digunakan adalah Steel, High Strength Low Alloy. Kemudian langkah kedua adalah pemilihan constraint. 
Constraint yang digunakan adalah fixed constraint. Bidang yang dijadikan constraint dapat dilihat pada Gambar 9.

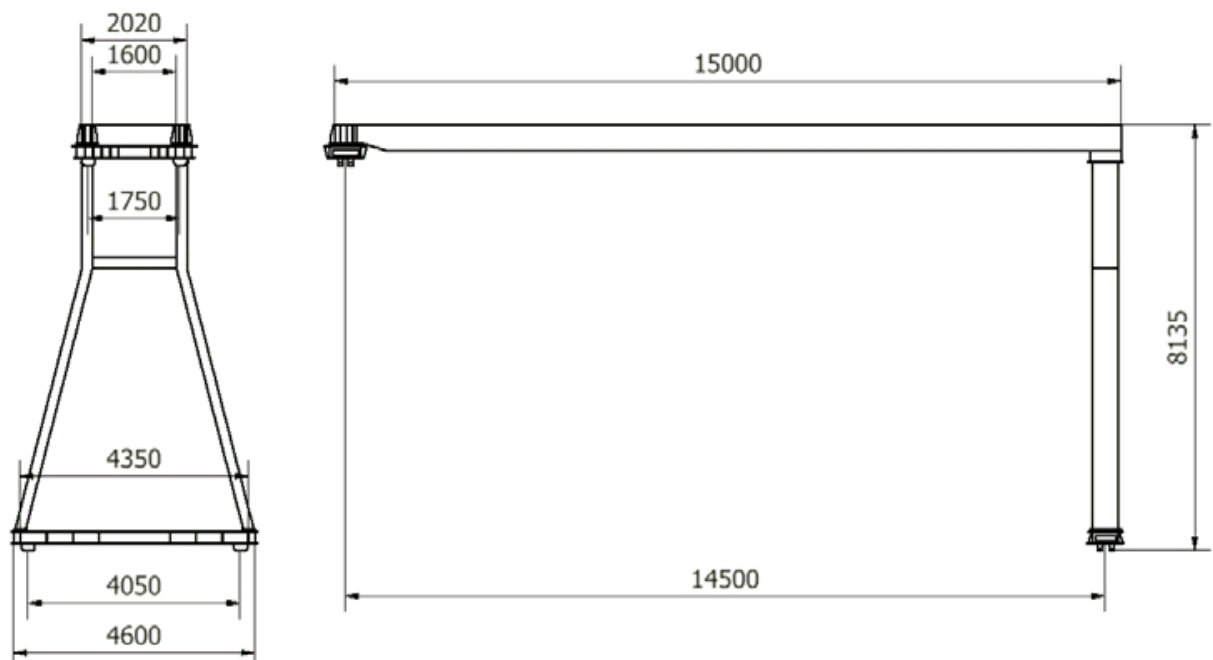

Gambar 8. Dimensi utama semi gantry crane

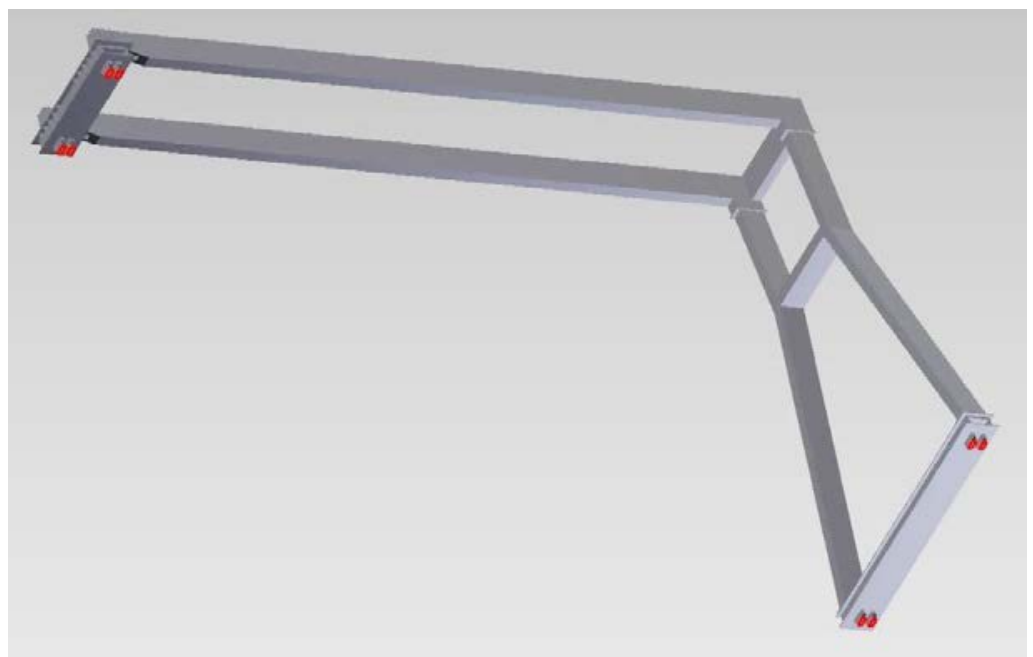

Gambar 9. Bidang yang dijadikan constraint.

Lalu langkah terakhir adalah pemberian beban kepada model. Beban yang dialami oleh model adalah pembebanan akibat muatan $11000 \mathrm{~kg}$ yang diangkat, dimana beban tersebut memiliki nilai 107910 N. Selain akibat beban muatan yang diangkat, terdapat pula beban akibat berat model itu sendiri yang dipengaruhi oleh gravitasi. Gaya gravitasi pada model dapat dilihat pada lingkaran yang memiliki warna hijau.

Pembebanan yang terjadi dibagi menjadi empat bagian dengan nilai masing-masing beban adalah 26977,5 N, karena diasumsikan beban terdistribusi secara merata ke semua roda trolley yang berjumlah empat. Pembebanan pada gambar 10 dilakukan dengan mengambil jarak $600 \mathrm{~mm}$ (horizontal) dari titik tengah bidang dan $1800 \mathrm{~mm}$ untuk jarak antarbeban secara vertikal.

Pembebanan dilakukan juga pada bagian kiri dan kanan girder dengan mengambil jarak sebesar $600 \mathrm{~mm}$.

\section{Stabilitas}

Diasumsikan pada Gambar 11 bahwa trolley crane berada pada kedudukan terujung, arah gaya akibat muatan $Q$ dan trolley $G_{0}$ akan melewati tepat pada bagian bawah rel. 




Gambar 10. Pembebanan di bagian tengah girder

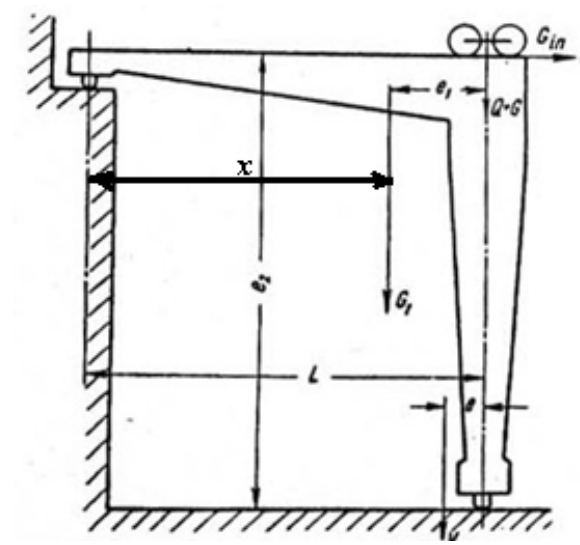

Gambar 11. Diagram untuk memeriksa stabilitas struktur rangka [1]

Maka, dengan menandai bobot rangka crane dengan $G_{1}$ dan gaya inersia ketika trolley direm $G_{i n}$, didapatkan jarak antara resultan $V\left(=Q+G_{0}+G_{1}\right)$ dan sumbu rel penumpu.

\section{Daya Motor}

Pada perancangan ini digunakan tenaga penggerak dengan daya yang berasal dari motor listrik untuk gerakan hoist, gerakan trolley, dan gerakan gantry. Gambar diagram motor listrik untuk gerakan hoist dapat dilihat pada Gambar 12.
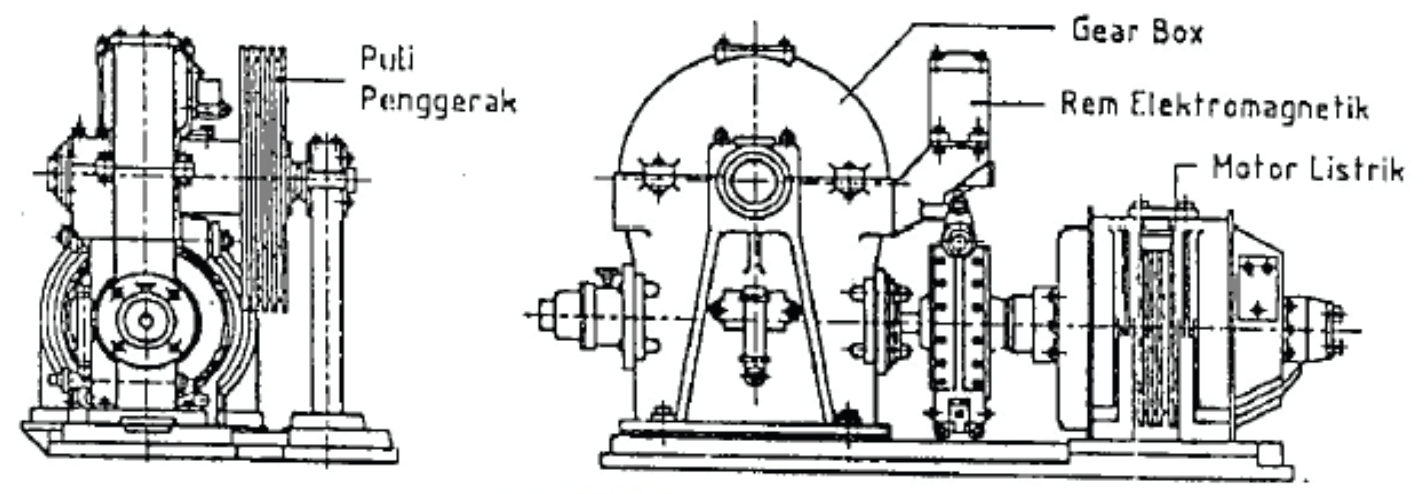

Gambar 12. Motor listrik untuk gerakan hoist [5]

\section{HASIL DAN PEMBAHASAN \\ Perhitungan Hoist}

Tali baja

Tipe konstruksi tali baja yang digunakan adalah 6x37 IWRC - Steel Core Grade G dengan arah pilinan berlawanan (ordinary lay) dan posisi pilinan sejajar (parallel lay). Susunan tali baja 
jenis ini terdiri dari 6 strand yang masing-masing terdiri dari 37 kawat berdiameter sama dengan core dari IWRC (Independent Wire Rope Core) - Steel Core. Tali baja memiliki diameter $(d)=18$ $\mathrm{mm}$; berat tali $(W)=1,29 \mathrm{~kg} / \mathrm{m}$; beban patah $\left(P_{b}\right)=174618 \mathrm{~N}$; dan tegangan patah $\left(\sigma_{b}\right)=1471,5$ $\mathrm{N} / \mathrm{mm}^{2}$.

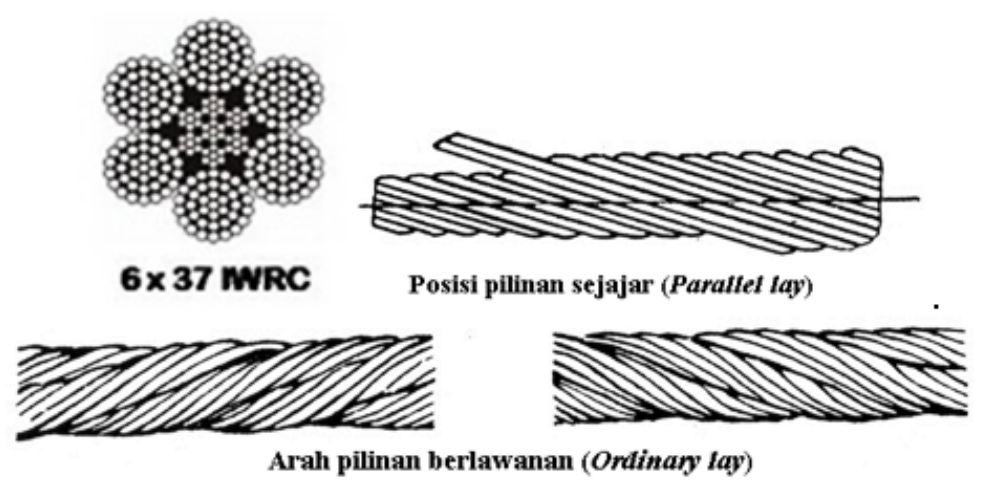

Gambar 13. Konstruksi tali baja [1]

\section{Puli}

Puli untuk perancangan ini menggunakan puli yang memiliki diameter $420 \mathrm{~mm}$ yang terbuat dari besi cor. Diameter roda puli untuk tali berdiameter $18 \mathrm{~mm}$ dapat dilihat pada Tabel 1.

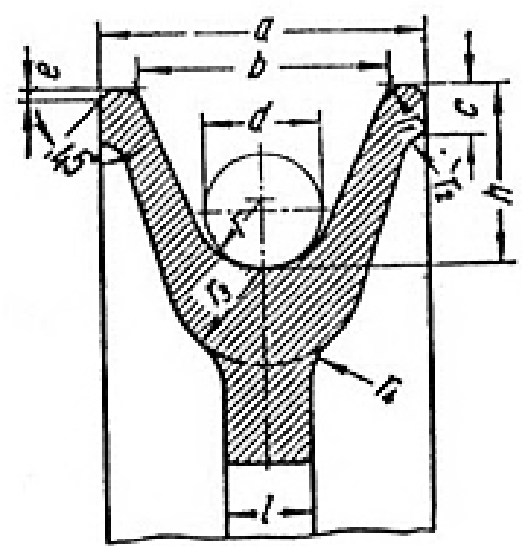

Gambar 14. Dimensi roda puli [1]

Tabel 1. Dimensi roda puli (mm)

\begin{tabular}{cccccccccccc}
\hline Diameter tali & $a$ & $b$ & $\mathrm{c}$ & $\mathrm{e}$ & $\mathrm{h}$ & $\mathrm{l}$ & $\mathrm{r}$ & $\mathrm{r}_{1}$ & $\mathrm{r}_{2}$ & $\mathrm{r}_{3}$ & $\mathrm{r}_{4}$ \\
\hline 18 & 50 & 37 & 9 & 1,4 & 28,5 & 13,5 & 11 & 5 & 4,5 & 15,5 & 9,5 \\
\hline
\end{tabular}

\section{Drum}

Diameter drum pada perancangan ini sama dengan diameter puli yaitu $D_{\min }=420 \mathrm{~mm}$ dan memiliki panjang total $850 \mathrm{~mm}$ serta tebal dinding drum yang terbuat dari besi cor adalah $20 \mathrm{~mm}$. Drum memiliki alur heliks dengan kisar $21 \mathrm{~mm}$ dan jumlah lilitan 15.

Kait

Kait yang digunakan adalah tipe kait tunggal dengan ulir trapesium dengan tipe TR 60x3 dengan spesifikasi teknis $d_{1}=56,5 \mathrm{~mm} ; d_{0}=60 \mathrm{~mm}$; serta $t=3 \mathrm{~mm}$ serta tinggi ulir $33 \mathrm{~mm}$.

\section{Batang lintang kait}

Momen lentur maksimum terjadi pada bagian tengah batang lintang kait sebesar 17265600 Nmm yang menyebabkan tegangan sebesar 310,42 MPa. 


\section{Perhitungan Struktur Rangka \\ Von mises stress}

Dari simulasi stress analysis, diperoleh hasil von mises stress yang menunjukkan nilai tegangan yang terjadi akibat pembebanan yang diberikan. Hasil von mises stress yang terjadi digambarkan pada model dengan pemberian warna, dimana warna biru adalah daerah yang mengalami tegangan yang aman dan warna merah adalah daerah yang mengalami tegangan yang kritis. Nilai tegangan yang ditunjukkan pada gambar-gambar di bawah ini adalah nilai minimum, nilai maksimum, dan nilai yang terjadi pada bagian tengah girder.

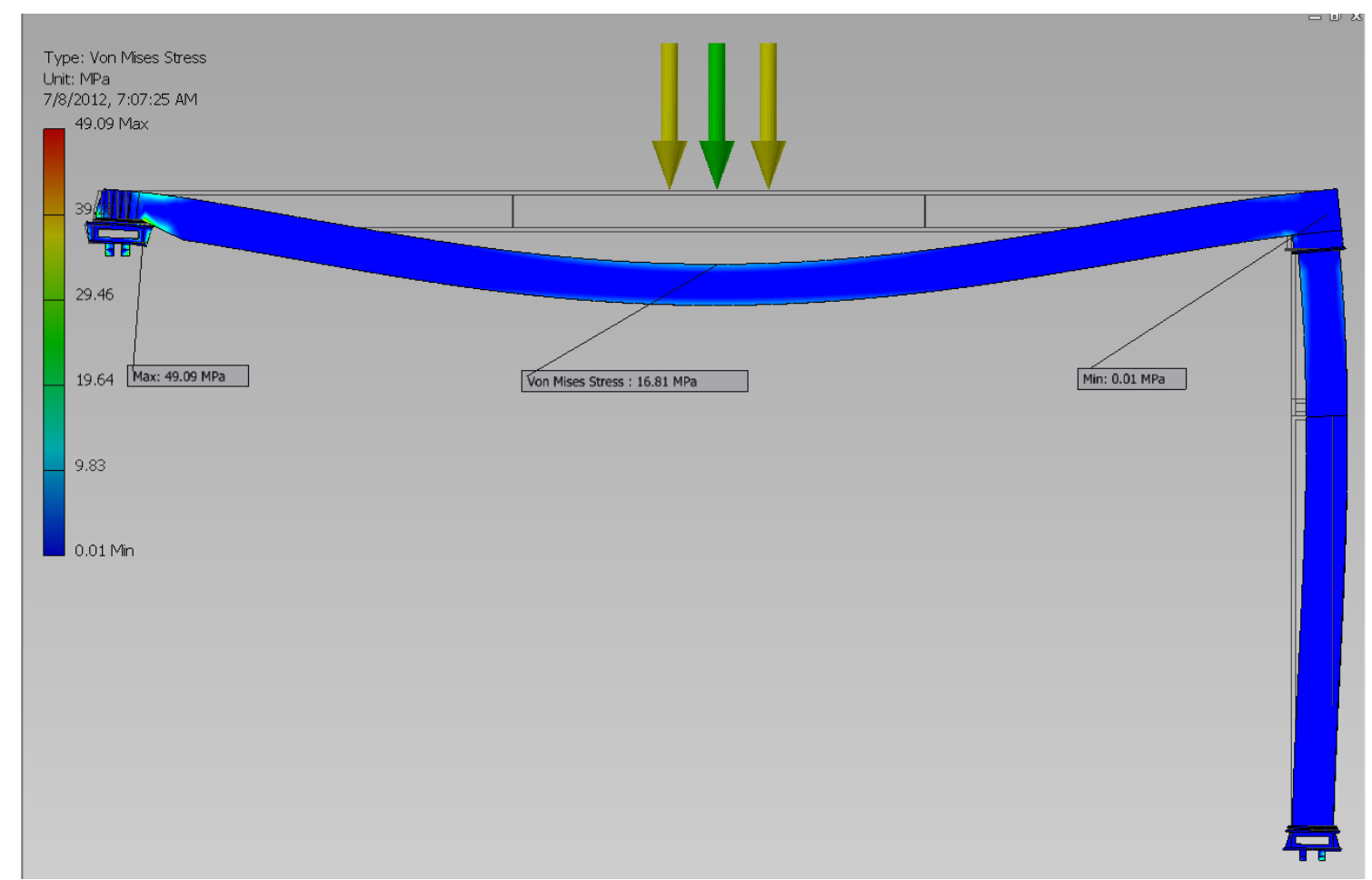

Gambar 15. Von Mises Stress untuk pembebanan di bagian tengah girder

Tabel 2. Hasil von mises stress

\begin{tabular}{ccccccc}
\hline \multirow{2}{*}{ Beban } & $\begin{array}{c}\text { Von Mises Stress } \\
\left.\left(\boldsymbol{\sigma}_{\boldsymbol{v} m}\right) \mathbf{( M P a}\right)\end{array}$ & $\begin{array}{c}\text { Yield } \\
\text { Stress } \\
\left(\boldsymbol{\sigma}_{\text {yield }}\right) \\
\mathbf{( M P a )}\end{array}$ & $\begin{array}{c}\text { Design } \\
\text { Stress } \\
\left(=\boldsymbol{\sigma}_{\text {yield }} / \boldsymbol{S}_{\boldsymbol{f}}\right) \\
\left(\boldsymbol{S}_{\boldsymbol{f}}=\mathbf{4}\right) \\
(\mathbf{M P a})\end{array}$ & $\begin{array}{c}\text { Load Factor } \\
\left(=\boldsymbol{\sigma}_{\text {yield }} / \boldsymbol{\sigma}_{\boldsymbol{v}}\right)\end{array}$ & Keterangan \\
\cline { 2 - 6 } & Maksimum & Tengah & & \\
\hline Tengah & 49,09 & 16,81 & 275,8 & 68,95 & 5,618 & Kuat \\
Kiri & 58,21 & 17,57 & 275,8 & 68,95 & 4,738 & Kuat \\
Kanan & 43,52 & 17,31 & 275,8 & 68,95 & 6,337 & Kuat \\
\hline
\end{tabular}

Dari tabel di atas dapat dilihat bahwa nilai von mises stress maksimum untuk ketiga simulasi masih di bawah nilai design stress [3] dan nilai load factor berada di atas nilai safety factor $\left(S_{f}\right)$ [3]. Maka dari itu, rancangan ini kuat.

\section{Displacement}

Dari simulasi stress analysis, diperoleh hasil displacement yang menunjukkan nilai defleksi yang terjadi akibat von mises stress. 


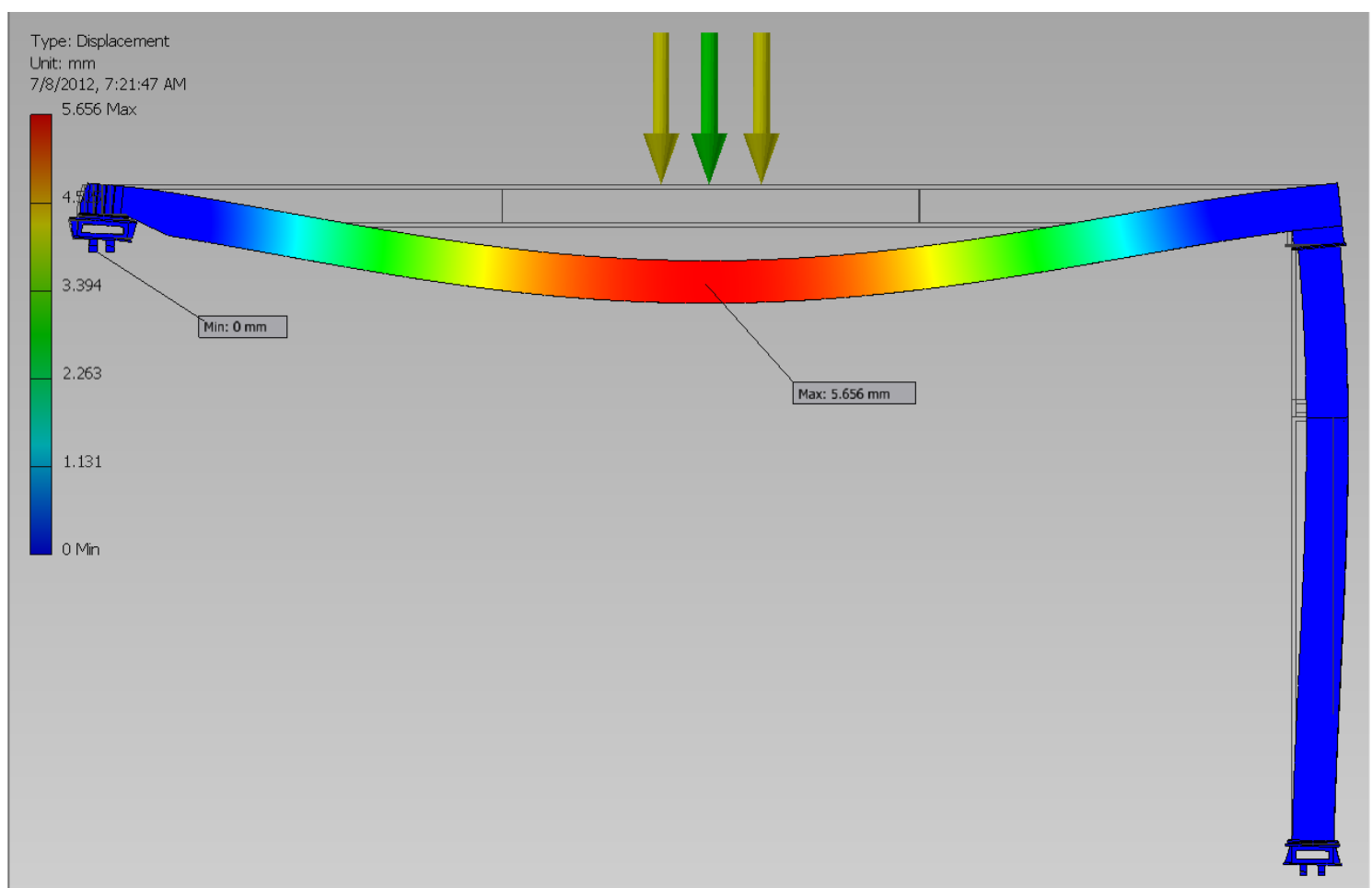

Gambar 16. Displacement untuk pembebanan di bagian tengah girder

Tabel 3. Hasil displacement

\begin{tabular}{cccc}
\hline Beban & Displacement $(\mathrm{mm})$ & $\begin{array}{c}\text { Batas Aman }(=\text { Span/700) } \\
\text { (Rudenko, 1994;331) }(\mathrm{mm})\end{array}$ & Keterangan \\
\hline Tengah & 5,656 & 21,428 & Aman \\
Kiri & 5,717 & 21,428 & Aman \\
Kanan & 5,659 & 21,428 & Aman \\
\hline
\end{tabular}

Melihat data-data yang ada pada Tabel 3, didapatkan kesimpulan bahwa nilai displacement yang terjadi pada struktur rangka masih dapat ditoleransi karena tidak melebihi batas aman.

\section{Stabilitas}

Jarak antara resultan $V$ dan sumbu rel penumpu yang diperoleh dari perhitungan sebesar $0,373 m$ sehingga nilai $\psi$ yang diperoleh adalah 1,026. Nilai $\psi$ tersebut masih di bawah nilai yang diizinkan.

\section{Daya Motor}

Daya motor untuk gerakan hoist yang diperoleh dari perhitungan sebesar $40 \mathrm{HP}$, kemudian untuk gerakan trolley sebesar 25 HP lalu untuk gerakan gantry sebesar 75 HP.

\section{KESIMPULAN}

Berdasarkan hasil perancangan yang telah dilakukan, maka kesimpulan yang pertama adalah tali baja yang digunakan memiliki tipe 6x37 IWRC - Steel Core Grade G dengan spesifikasi teknis: diameter $18 \mathrm{~mm}$; berat 1,29 kg/m; beban patah $174618 \mathrm{~N}$; tegangan patah 1471,5 N/mm² dan umur tali 24 bulan. Kesimpulan yang kedua adalah jenis sistem puli yang digunakan sistem puli majemuk dengan empat bagian yang memiliki efisiensi 0,94. Diameter puli sebesar $420 \mathrm{~mm}$ dan puli terbuat dari besi cor. Kesimpulan yang ketiga adalah drum yang digunakan memiliki diameter $420 \mathrm{~mm}$ dan panjang $850 \mathrm{~mm}$ yang terbuat dari besi cor serta memiliki efisiensi 0,95. 
Kesimpulan yang keempat adalah kait yang digunakan merupakan kait tunggal yang terbuat dari baja 20. Ulir pada tangkai kait menggunakan ulir trapesium TR60x3. Kemudian untuk batang lintang kait, bahan yang digunakan adalah baja karbon dengan tegangan maksimum terjadi pada bagian tengah yaitu sebesar 310,42 MPa. Kesimpulan yang kelima adalah struktur rangka yang didesain merupakan double girder semi gantry crane dengan span $15 \mathrm{~m}$ dan tinggi angkat $8 \mathrm{~m}$. Material yang digunakan adalah Steel, High Strength Low Alloy dengan von mises stress maksimum sebesar 58,21 MPa dan displacement 5,717 mm serta nilai kestabilan struktur rangka sebesar 1,026. Kesimpulan yang terakhir adalah daya motor yang dibutuhkan untuk gerakan hoist sebesar $40 \mathrm{HP}$, untuk gerakan trolley sebesar $25 \mathrm{HP}$, dan untuk gerakan gantry sebesar $75 \mathrm{HP}$.

\section{DAFTAR PUSTAKA}

[1]. Rudenko, N., 1994, Mesin Pemindah Bahan, Erlangga, Jakarta.

[2]. Syamsir, A. Muin., 1990, Pesawat-pesawat Pengangkat, Edisi Pertama, PT. Raja Grafindo Persada, Jakarta.

[3]. Khurmi, R.S., J.K. Gupta, 2005, A Textbook of Machine Design, Eurasia Publishing House (PVT.) LTD., New Delhi.

[4]. Manurung, Fernando, 2009, Perancangan overhead travelling crane dengan kapasitas angkat 120 ton, dan perhitungan bahan crane pada pembangkit listrik tenaga air, Skripsi, Universitas Sumatera Utara. 